\title{
John Newdigate III, Gilbert Sheldon, and MS A414 106r
}

As we have seen, the Arbury Hall miscellany version of The Humorous Magistrate features heavy revisions throughout: words, phrases, and even entire passages are struck out, and new ones are sometimes added to replace them. ${ }^{1}$ Generally, revisions to the Arbury text bear no scribal commentary; the two manuscript versions of The Humorous Magistrate are themselves our primary evidence when attempting to discern any editorial rationale for revisions within and between them. A short note written vertically in the left-hand margin of page 106r is thus highly unusual in that it appears to be an editorial comment. Seemingly referring to Spruce's soliloquy incipit 'O Stupidity in the robes of Iustice', it reads 'This speach not so cleare $\&$ perspicuous' and is attributed to one 'Dr S.'.

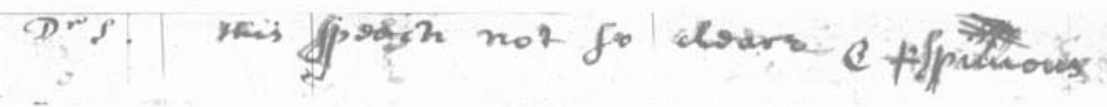

Fig. 1. Left-side marginal comment on Ms A414 106r, rotated 90 degrees clockwise and with nearby text cropped for clarity.

If John Newdigate III is indeed the manuscript's principal composer and scribe, as Kirsten Inglis and Boyda Johnstone convincingly suggest, then 'Dr S.' is very likely Gilbert Sheldon (1598-1677), Newdigate's long-time friend and correspondent. ${ }^{2}$ By providing us with a name as well as a sense of editorial intent, the comment on 106r offers some insight into the compositional process behind the play. To better understand the significance of this brief but remarkable note, we must first examine the part played in that process by John Newdigate's friend and mentor, Gilbert Sheldon.

As Felicity Heal and Clive Homes note, a university education offered numerous advantages to gentry sons in the seventeenth century. One of these was the opportunity to hone their interpersonal skills and begin cultivating 
the web of social contacts that would play an important role throughout their adult lives. ${ }^{3}$ While studying at Trinity College between 1618 and 1621, John Newdigate III and his younger brother Richard Newdigate did just this when they befriended Gilbert Sheldon, a fellow student who was then in the process of completing his MA. His friendship with John Newdigate III would last until the elder brother died in 1642 and he corresponded regularly with Richard Newdigate until his own death in 1677.4

Sheldon is by no means an obscure figure in English history, but like his twentieth-century biographer Vernon Staley, most historians have tended to focus on the storied events of his later life. 5 These include his monarchist allegiance during the civil war, his staunch defence of the Church of England during the Interregnum and Restoration, his rise through the clerical ranks to become Archbishop of Canterbury in 1663, and his charitable works during the 1660s and 70s - not least of which was his financial support in the construction of Oxford's Sheldonian Theatre. ${ }^{6}$ This emphasis is unsurprising, given Sheldon's important role in ecclesiastical and political history combined with the relative paucity of details about his early life. As John Spurr notes, however, Sheldon was a man of many interests, not all of which were limited to his religious vocation. ${ }^{7}$ His letters to John Newdigate, written throughout the 1620 s and 1630 s, not only offer a glimpse into his formative years and secular pursuits but also demonstrate his importance in the development of Newdigate's career as an amateur dramatist and poet.

According to Heal and Homes, university friendships were defined above all else by shared interests. ${ }^{8}$ In the case of Sheldon and Newdigate, these interests included current events, ${ }^{9}$ equestrianism, ${ }^{10}$ and — most significantly when considering the note on A414 106r - literature. As an increasingly learned man still actively connected to academia long after John had left Trinity, Sheldon took on the role of literary mentor to his younger friend, though as I will discuss below, he was always careful to demonstrate that he viewed John as a peer and colleague rather than a student. The mentorprotégé relationship finds expression in the following excerpt from one of Sheldon's letters, sent in 1623:

Sweet sir I am newly come to Oxford \& the hast of this messenger that intends a speedy returne calls vpon me for a letter, you must not expect (as you call them) stronge lines or Retoricall raptures which are fitter for a stage yan a letter \& rather ecclipse $\&$ shifte true affection, yan either manifest or increase it. ${ }^{11}$ 
In defending his customarily plain (and in this case also hastily written) style, we see Sheldon advocating for the use of language in accordance with genre. He suggests that personal communication between friends should be about sincere feelings simply phrased, arguing that the stage was a more appropriate place for what Newdigate had termed 'stronge lines'. The tone here is not one of condescension, but rather gentle chiding; Sheldon is taking up one side of the debate about ornate vs plain style that endured throughout the early modern era, with the expectation that his protégé might take up the other. ${ }^{12}$ Significantly, this letter demonstrates that the two men engaged in discussions about composition and rhetoric and it may even gesture to writings shared for review and critique.

Exchanges such as this one undoubtedly played a role in shaping Newdigate's approach to drama and literature but the greater part of Sheldon's influence probably came from the literary models he provided. With his connections in Oxford, Sheldon enjoyed access to many manuscripts and print volumes and would often forward them to his friend at Arbury. For example, a 1621 letter at the Warwickshire County Record Office mentions that Sheldon sent Newdigate a 'paper booke' while another from 1623 notes an enclosed 'coppy of verses.' ${ }^{13}$ He seems to have sought out works that would correspond to Newdigate's tastes; in 1627 he forwarded a manuscript copy of over thirty caricatures composed by Oxford-based cleric, scholar, and writer John Earle. Excerpted from Earle's Micro-Cosmographie, which was first published anonymously in 1628 , these glib prose pieces satirized everything from religious sceptics to plodding schoolboys to tobacco sellers. ${ }^{14}$ Satire was a genre which held great interest for Newdigate: he had purchased classics by Horace, Juvenal, Martial, and Persius during his university days and he wasted no time in copying Earle's work into his commonplace book. ${ }^{15}$ Intriguingly, Newdigate noted that the characters were 'bestowed upon' him 'by Mr G.S. April 20: 1627. In Mr Erles own copie'. ${ }^{16}$ It is not necessarily remarkable that Newdigate knew Earle's name; they had attended Oxford at the same time, and Earle's authorship of the Micro-Cosmographie was widely known despite the anonymous printing. ${ }^{17}$ What is unusual, however, is that Sheldon was able to send a copy well before the work was published. Even with his Oxford connections, obtaining a manuscript in Earle's own hand must have taken considerable effort. This suggests either that Newdigate had asked for a copy specifically or that Sheldon had recognized that the characters would be of particular interest to his friend. 
The caricatures, which occupy pages $83 \mathrm{r}-102 \mathrm{r}$ of Newdigate's commonplace book, are virtually identical to those that appeared in several 1628 editions. However, the order of the caricatures as copied in the commonplace book does not correspond to any of the 1628 editions, which are themselves quite disparate from one another in their sequencing. All of the editions also include several caricatures which do not appear in Newdigate's copy. Perhaps Newdigate was working from a manuscript which formed the basis of a first-run publication that no longer survives but more likely the publisher simply reorganized the text and incorporated more of Earle's material, which by this point had been in development for some ten years. ${ }^{18}$ In this case, we can reasonably conclude that Sheldon was able to proffer a manuscript well in advance of the printing stage, reinforcing the notion that the Micro-Cosmographie was of special significance to Newdigate. Some of the caricatures, furthermore, bear more than a passing resemblance to certain characters in The Humorous Magistrate. For example, the 'selfe conceited man' featured in all the 1628 editions and copied on 90r-91v of the commonplace book shares certain qualities with Thrifty: 'His discourse is all positions and definitive decrees, with thus it must be, $\&$ thus it is, and he will not humble his authority to proue it.' ${ }^{19}$

Earle's characters evidently captivated Newdigate's literary imagination and it is clear from the surviving letters that Sheldon sent many other texts for his perusal as well. The cleric did not merely acquire works of literature, however, but took it upon himself to vet them as well. Larminie notes that he obtained a copy of Bacon's Henry VII for Newdigate but made sure to read it first in order to ascertain whether it was worthy of the praise it had received. ${ }^{20}$ In this way, Sheldon took an active role in guiding Newdigate's literary development but as Larminie argues, he did so with the knowledge that his associate was an independent thinker capable of negotiating and interpreting complex texts on his own. ${ }^{21}$ In keeping with the egalitarian nature of their intellectual relationship, Sheldon was well aware that his friend's eye might settle on different merits and qualities than he had perceived himself.

With this context in mind, let us return to the note on 106r: 'Dr S. This speach not so cleare \& perspicuous'. It immediately tells us two things: first, that Sheldon read the Arbury manuscript and offered Newdigate some advice on improving it, and second, that the revision date for the Arbury manuscript cannot have been earlier than mid-1634, for Sheldon did not receive his Doctor of Divinity degree until 25 June of that year. ${ }^{22}$ This aligns 
with Polito and Windle's conclusion that the later Osborne manuscript was penned in 1640 and allows ample time for the production of any now-lost intermediary texts which Kidnie speculates must have come between the two versions. ${ }^{23}$ Furthermore, a process of composition and revision spanning several years corresponds to Inglis and Johnstone's characterization of Newdigate as a man who was constantly striving to improve both the form and content of his written works. ${ }^{24}$

A new possibility arises: could Sheldon somehow have been directly involved in the production or revision of the Arbury manuscript? As intriguing as the idea of a dramatic collaboration between the two former schoolmates might be, it seems unlikely for both paleographical and contextual reasons. Despite the small sample size, it appears that the marginal comment on 106r was not written by Sheldon but rather by Newdigate. Assuming that the Arbury Ms was being revised in 1634, or perhaps a few years later, a letter from Sheldon written 15 October 1635 offers a nearly contemporaneous writing sample for comparison. ${ }^{25}$ Though badly damaged, this missive clearly displays Sheldon's bold, angular secretary hand. In particular, Sheldon forms his miniscule letter $p$ in a two-stroke process, with a simple descender followed by a loop. The two $p$ s in the comment, however, clearly display a descender overwritten by an ascender which then curls down to form the loop, all in one stroke. Sheldon also lifts his pen from the page frequently, resulting in faint or sometimes nonexistent ligatures; by contrast, in the comment we see pronounced ligatures indicative of a flowing cursive hand. The $h$ in the comment also features a slight serif, examples of which are absent from the $h s$ in Sheldon's hand even when they appear at the end of a word. Finally, the note makes use of the same abbreviation for 'per' (transcribed by Kidnie as $j$ ) that is found throughout the rest of the Arbury manuscript in such words as 'paper' (572, 1173, and 2728), 'perfect' (494, 710, and 920 among others), and 'person' (189, 1772, and 1825 among others).

The inclusion of Sheldon's doctoral title in the attribution also suggests that he did not write the note himself. In Sheldon's letters to the Newdigate brothers, despite the titles and positions he accumulated - his doctorate in 1634, the bishopric of London in 1660, the archbishopric of Canterbury in 1663 - he always remained on an intimate, informal basis with his old friends. The actual signature varies: sometimes it is 'G.S.' while in other instances he signs himself 'Gilb: Sheldon' or more rarely 'G. Sheldon'. ${ }^{26}$ When his name does appear with a title on a letter to John or Richard, it is added by a later hand - most likely that of Richard Newdigate II (1644-1710), who 
labelled and catalogued many of his family's letters in the late seventeenth century. ${ }^{27}$ By contrast, in letters to less intimate correspondents Sheldon does not hesitate to disclose his office. For example, in a 1664 letter to Richard II he signs himself 'Gilt: Cant:', indicating his ascension to the archbishopric the previous year. ${ }^{28}$ Sheldon's humble and amicable tone when writing to his old schoolmates, combined with his consistent omission of his own titles, suggests once again that he saw his friendship with the early seventeenthcentury Newdigate brothers as a bond between peers.

It follows that rather than denoting Sheldon's own writing, the attribution to 'Dr S.' is more likely indicative of John's deference to his learned friend on literary and rhetorical matters, in much the same way as he would trust Sheldon's judgment in proffering worthy texts for reading and study. The most probable scenario is that Sheldon - and quite possibly others ${ }^{29}$ — read the Arbury manuscript (or perhaps witnessed or even took part in a staged reading or performance) and offered comments verbally or in documents that have not survived. In the process of editing 106r, Newdigate seems to have written one of these comments down, perhaps for later reference, and in so doing has left a small but enticing clue into his compositional process.

We might well wonder: was Sheldon's comment taken to heart? I suggest that it was. Even amid the generally dense revisions of the Arbury manuscript, those found in Spruce's soliloquy are unusual. Throughout the rest of the text, full-line excisions usually come in groups because an entire section of dialogue is being removed. In Kidnie's Malone Society edition, we see this at 121-6, where Thrifty's parting words to Spruce are truncated to a single line, and at 1798-1813, where Wild's attempts to assure Mistress Mumble of his worthiness are cut down by more than half. By contrast, most of the revisions in Spruce's soliloquy do not attempt to excise but rather to rewrite. Let us consider lines 136-41, in which Spruce takes aim at Thrifty's comical use of cap-paper - a kind of low-quality brown paper used by tradesmen to wrap their wares - when penning his judicial pronouncements. ${ }^{30}$ Line 139 has been struck out, while the small size and cramped positioning of line 141 suggest that it is an addition. The original text would therefore read as follows:

How miserably plagud is my deare Constance to haue such a thing to her father as cannot read english but in his Clerks hand nor euer writ 
once when Parchment was out oth' way vpon cap paper

superscription but to the Constable \& his deputy.

With the excision of line 139 and the addition of 141, however, the passage becomes:

How miserably plagud is my deare Constance to haue such a thing to her father as cannot read english but in his Clerks hand nor euer writ superscription but to the Constable $\&$ his deputy $\&$ that vpon cap paper.

$(136-8,140-1)$

While the comical juxtaposition of scribing legal documentation on cap paper is retained, the second passage is undoubtedly more logical and accessible. With the exception of line 135 ('now thou hast a daughter I wish thee gelded') which might have been removed because of its uncharacteristic viciousness, most of the changes are similarly intended to increase the flow and readability of the passage. Lines 152-4 show revisions for grammar and syntax, for example, while on 155 Newdigate has scratched out first 'prize' and then 'price' before settling on 'gem' to describe Constance as an object of longing.

All in all, there are 33 additions and 55 excisions throughout the passage. ${ }^{31}$ While other sections of the text match this density of revision, often where large sections of dialogue are introduced or removed, there are none that exceed the number of combined excisions and additions within the same number of lines. This suggests that Newdigate was generally pleased with the tone and rhetoric of Spruce's soliloquy, but agreed with Sheldon that it needed to be made more 'cleare and perspicuous'. It is indeed a critical dialogue, providing exposition on the two central characters - Spruce and Thrifty - and establishing much of the context for what is to follow. Though it is difficult to speculate on why this particular comment was written down, it may well have been because of its perceived importance.

Though there is no concrete evidence to suggest that Gilbert Sheldon was directly involved in composing or revising the Arbury manuscript, he remains a significant figure when considering the growing corpus of works associated with John Newdigate III. Sheldon's mentorship and the texts he provided can be used to establish Newdigate's literary foundations and to understand and analyze his compositions. In many ways, The Humorous Magistrate represents a culmination of the interests Sheldon had helped 
foster in his younger friend: satire, drama, and 'stronge lines' used in the right places. When John Newdigate III offered his writings to friends for their enjoyment and comment, Sheldon was no doubt among the first to be solicited, and — as in the case of Spruce's soliloquy — it is not unreasonable to assume that other revisions to the Arbury manuscript were also made at his behest. If this is indeed the case, then Gilbert Sheldon can be said to have exerted a considerable, albeit indirect, influence on the development of The Humorous Magistrate.

\section{Notes}

1 I hereafter refer to the Ms A414 text of The Humorous Magistrate as the Arbury version and the University of Calgary Special Collections Msc 132.27 text as the Osborne version. Both versions can be found in the Malone Society's editions of The Humorous Magistrate (Manchester, 2011). The Arbury play has been transcribed and edited by Margaret Jane Kidnie, while the Osborne version has been correspondingly prepared by Jacqueline Jenkins and Mary Polito.

2 Kirsten Inglis and Boyda Johnstone, “The Pen lookes to be canoniz'd": John Newdigate III, Author and Scribe' in this special issue of Early Theatre.

3 Felicity Heal and Clive Holmes, The Gentry in England and Wales (Palo Alto, 1994), 286.

4 Though I concentrate here on the relationship between Gilbert Sheldon and John Newdigate III because of its potential implications for The Humorous Magistrate, Richard Newdigate's fifty-year friendship with Sheldon is, if anything, better attested to by extant documents. It has also received more scholarly attention from ecclesiastical and political historians because of its professional component - as a lawyer, Richard Newdigate sometimes provided legal services to Sheldon and the universities with which he was associated and posted the clergyman's bail when Sheldon was imprisoned in 1648. In return, Sheldon was his confidant, advisor in both temporal and spiritual matters, and even matchmaker for his children. See Vivienne Larminie, Wealth, Kinship, and Culture: The Seventeenth-Century Newdigates of Arbury and their World (Rochester, 1995), 134.

5 Vernon Staley's 1913 Life and Times of Gilbert Sheldon (Charleston, 2009) is the only book-length work devoted fully to Sheldon's life, though many historians have discussed the important role he played in the seventeenth-century English church.

6 It is tempting to read Sheldon's generous patronage of the theatre that bears his name as an indication of interest in drama and performance even in his later life. 
In the seventeenth century, however, it appears that the Sheldonian Theatre was largely confined to graduation and degree ceremonies. Until its construction, these sometimes rowdy events had been held in Oxford's Church of St Mary the Virgin and university officials were anxious for a new venue that would allow the church to retain its solemnity during matriculation season. See Adrian Tinniswood, His Invention So Fertile: A Life of Christopher Wren (Oxford, 2001), 102. Nevertheless, it is not inconceivable that plays or musical performances could have been scheduled at the Sheldonian when no official functions were taking place, as is the case today.

7 John Spurr, Sheldon, Gilbert, DNB.

8 Heal and Homes, Gentry, 269.

9 Spurr, 'Sheldon'. For more information on Sheldon as a provider of news, see Larminie, Wealth, 162-3.

10 In a 1622 letter (wCro CR 136 B 476), Sheldon notes his intention to see a horse race with John. A subsequent letter dated 1623 mentions some horse-racing wagers placed by Richard, and describes several fine specimens entered by the Duke of Buckingham in an upcoming competition in order to keep John abreast of the developments: 'these are all besides thate you know that shal runne for the cup' (wCro CR 136 B 481). For more on equestrianism and horse-racing in The Humorous Magistrate, see Vimala Pasaputhi, 'Jockeying Jony: Horse-Racing and Regional Identity in The Humorous Magistrate' in this special issue of Early Theatre.

11 wCro CR 136 B 479.

12 For a more detailed discussion of the early modern debate on ornate vs plain style, see Heinrich Plett, Rhetoric and Renaissance Culture (Boston, 2004), particularly the chapter 'Shakespeare and the Ars Rhetorica'.

13 wCro CR 136 B 473 and wCro CR 136 B 480. Vivienne Larminie further discusses Sheldon as a provider of literature in Wealth, Kinship, and Culture, 159.

14 John Earle. Micro-Cosmographie. Or, A Peece of The World Discouered in Essayes and Characters (London, 1628, sTC 780:09). ЕEBO. In addition to three 1628 editions, ЕЕВO provides a further nine editions printed between 1629 and 1669 .

15 For a list of other books purchased by Newdigate, mostly during his time at Trinity, see Larminie, Wealth, 195-6.

16 Bodleian Library Eng. Poet Ms e.112, 102r.

17 Mohit K. Ray, (ed.), 'John Earle (1601-65)', The Atlantic Companion to Literature in English (New Delhi, 2007), 156.

18 Ibid.

19 Earle, Micro-Cosmographie. EEBO. The 'selfe-conceited man' is the twelfth caricature to appear in all three of the 1628 editions of Earle's Micro-Cosmographie. The different versions supply minor corrections, suggesting a sequence of revision and 
publication. STC 780:09, from which this citation is drawn, appears to be the most emended of the 1628 editions.

20 Larminie, Wealth, 159.

21 Ibid, 159.

22 Staley, Sheldon, 8.

23 Mary Polito and Jean-Sébastien Windle argue for a composition date of 1640 based on historical and cultural references within the play in "You see the times are dangerous": The Political and Theatrical Situation of The Humorous Magistrate (1637)', Early Theatre 12 (2009), 109. Margaret Jane Kidnie suggests that one or more intermediary versions would have been produced before this edition, reflecting the development of changes first evinced in the Arbury ms. See 'Near Neighbours: Another Early Seventeenth-Century Version of The Humorous Magistrate', English Manuscript Studies, 1100-1700 13 (2007), 200.

24 Inglis and Johnstone, 'The Pen'.

25 wCro CR 136 B 484.

26 Of the documents at the Warwickshire County Record Office, letters where Sheldon signs himself 'G.S.' include CR 136 B 749, 484, and 486. Letters featuring the 'Gilt: Sheldon' signature include CR 136 B 474, 476, and 483, among others.

27 E-mail from Vivienne Larminie to the author, November 2010. I would like to thank Dr Larminie for taking the time to share her expertise and insight on the Newdigate family with a young scholar such as myself.

28 wCro CR 136 B 489.

29 As Larminie notes, many Newdigate contacts were sustained at least in part by the exchange of writings; these included the Burdetts, Gresleys, and Willoughbys. Literary interests also linked John Newdigate III to Richard Fallowfield and Edward Stapleton (Wealth, 172).

30 In this context, 'cap-paper' refers to a type of brownish paper used by merchants and grocers to pack their wares (OED 1). It would certainly not have measured up to the high-quality leaves on which judicial orders were typically penned. The Humorous Magistrate retains cap-paper's commercial symbolism, suggesting that both Thrifty's pronouncements and his very position as magistrate are rooted in financial transactions rather than legitimate judicial authority.

31 This number includes some words and letters that have been added and then struck out, qualifying them as both additions and excisions. As readers of Kidnie's Malone edition will see, despite the density of revisions in the Arbury manuscript, Newdigate did scholars a favour by marking his additions on both sides with a character resembling the number 8 set at a 45 -degree angle. 